\title{
Lakatos, Columbus and the expectations of research impact on practice
}

\author{
Jeppe Skott ${ }^{1}$ \\ Published online: 3 July 2020 \\ (c) Springer Nature B.V. 2020, corrected publication 2020
}

Over the last 30 years suggestions for reform in mathematics education have changed the dominant perspective on learning and extended the curricular ambitions of the subject. Students are no longer expected merely to take over pre-developed concepts and procedures in ready-made form. To engage them in genuine mathematical activity, the reform supplements and combines content areas such as number and operations, algebra, geometry, and stochastics with an emphasis on mathematical processes or practices. These processes include problem solving, reasoning and proving, modelling, and communicating, each of which is both an aim in its own right and a means to learning other contents. The significance of these processes have been highlighted, for instance by Schoenfeld (2009), who likened problem solving to the heart of mathematics and proving to its soul, the point being not only that the two go together, but that their combination is a sine qua non of mathematics. The implicit question, then, is why the school subject should be called mathematics, if these mathematical practices do not play prominently in students' opportunities to learn.

Reform recommendations, however, do not materialise easily, and in spite of comprehensive developmental initiatives, the results are often disappointing. Cai et al., for instance, refer to experiences from the USA, where "[c]lassroom teaching [...] has, in most cases, remained stubbornly focused on a narrow, unambitious set of learning goals and has continued to use mostly recitation techniques with few rich learning opportunities" (Cai et al. 2019). There is ample evidence to suggest that the situation is similar in many other countries.

Often, the problems of introducing the reform are explained with reference to the complexities of teaching, as the reform requires the teacher to play a different and more prominent role for learning and lives as they unfold in mathematics classrooms. Content-related challenges include selecting, developing and using tasks that have the potential to engage students in mathematical processes in order for them to gain proficiency with the processes themselves (e.g. problem solving) as well as profound understanding the content area in question (e.g. algebra). In the classroom, the teacher is required at the instant to capitalise on the mathematical potential of students' creative (and not-so-creative) responses to these

The original version of this article was revised: The author name has been missed out in the original publication of the article. It has been corrected now.

Jeppe Skott

Jeppe.skott@lnu.se

1 Department of Mathematics, Linnaeus University, 35195 Växjö, Sweden 
open and investigative tasks. This requires that teachers' understandings of the mathematical enterprise and of the related teaching-learning processes align with the priorities of the reform. The four articles in this issue of JMTE in different ways address these challenges.

\section{The four papers in the present issue}

Two of the papers in this issue consider how to support teachers in developing their capacity to select and develop tasks for teaching. Cooper, Olsher, and Yerushalmy acknowledge the difficulties involved, when teachers are to select suitable tasks, and they are concerned with the limitations of standard search engines, when teachers navigate the internet to do so. In response, they have developed and are now investigating the potentials of two related tools that are to assist teachers in making qualified choices as they select among the resources available. One tool allows teachers to tag resources with prescribed metadata developed by the researchers themselves; the other tool is a dashboard that is to assist teachers in selecting among resources that are already tagged. The tools and the metadata are considered boundary objects between two distinct discursive communities, the teachers and the researchers. They are to support teachers' instructional decisions as well as contribute to their professional development. In this article, the authors focus on the latter aspect, and present an analysis of how groups of practising and prospective teachers in Israel use the dashboard when planning an instructional sequence. Cooper, Olsher, and Yerushalmy argue that the categories of metadata do indeed function as boundary objects and conclude that the teachers are learning in the sense that they engage differently in curricular discourse, even though they do not always do it as expected by the researchers.

Leavy and Hourigan are also concerned with the character of the tasks teachers use, in particular when their students are to solve mathematical problems. If problem solving is to become a valuable learning experience for the students, the character of the problems they work with is of obvious importance. Leavy and Hourigan point out, however, that other studies have documented that teachers may find it difficult to select or develop worthwhile problems for their students to solve, and they refer to teachers' beliefs-based on their prior educational experiences — as an explanation. The study by Leavy and Hourigan is on the outcomes of a three-week instructional unit for prospective primary teachers in Ireland. The unit is on problem solving and problem posing, and the questions in the paper are whether the participants change their beliefs about what a mathematical problem is as they participate in the unit, and whether there is a shift in the types of problems they pose for students in primary school. The answer to both questions is in the affirmative. The 415 participants in the study generally use more varied and multifaceted terminology about mathematical problems at the end of the unit, and a somewhat similar change appears in the problems they pose for their prospective students. Although there is still room for improvement, the fairly optimistic conclusion is that even a short intervention may change prospective teachers' understanding of and approach to mathematical problems and problem posing.

The paper by Davis, Towers, Drefs, and Friesen is also in belief research. Their study follows from a master's programme in which teachers from a school in Canada with a strong tradition for innovation were introduced to important issues in mathematics education research. Davis and his colleagues were initially encouraged by how the participants aligned with the reform rhetoric of the programme. However, a year later there was little evidence of the reform in the mathematics classrooms at the school, and the research team 
was puzzled by the apparent conflict between how conversant the participants were with the reform discourse and the traditions that in some cases dominated classroom practices. Consequently, the team shifted its focus from the terminology the teachers used in interviews to the "implicit webs of associations", that is, to the metaphors the teachers seemed to draw on, when talking about mathematics teaching and learning. Davis et al. found greater consistency between beliefs and practice when they analysed beliefs from that perspective, than when they attended merely to teachers' explicit statements. The moral of the story is that belief research may overcome some of its conceptual and methodological problems, if beliefs are inferred or attributed to teachers on the basis of implicit webs of association rather than on explicit terminology. Considering teacher education and development, Davis et al. hypothesise that there may be potential in "attention to and interruption of metaphors and habits of association" and that simultaneous attention to "habits of speaking and teaching practices" is needed.

Research on teachers' beliefs is generally based on the assumption that these elusive mental constructs play prominently in classroom practice. Being less concerned with teacher characteristics (e.g. beliefs) than with the acts of teaching, research on teacher noticing has focused on what teachers attend to in instruction, how they interpret it, and how they respond. In programmes for teacher education and development, video has been used to develop teachers' capacity to notice student thinking. In their study from the USA, Walkoe, Sherin and Elby use video for another purpose. They study prospective teachers' (PSTs') tagging of video clips and the interpretations the participants make of the moments they tag. They do so to investigate the potentials of tagging tools for developing understandings of teacher noticing. In particular, their goal is "to illustrate the affordances of tagging tools for exploring relationships between PSTs' attention and interpretations". The 13 PSTs in the study tag video recordings before, during and after an intervention that is to support their noticing of students' algebraic thinking. The data include examples of different PSTs, who attend to the same moments, but interpret them differently; of the same PSTs, who attend to the same moments before and after the intervention, but changed their interpretation of the tagged moment; and the same PSTs who attend to different moments, but show few signs of developing their interpretive stance. Walkoe et al. conclude that tagging tools may be used productively to develop further understandings of teacher noticing as well as to support teacher educators in the difficult task of developing PSTs' capacity to notice students' mathematical thinking.

\section{What (not) to expect in terms of "impact"}

I introduced this editorial by referring to aspects of the current reform and to what is often presented as the disappointing results of reform initiatives. It is certainly not new in education to point to discrepancies between the ambition of reformers and the outcomes of their efforts. In mathematics education and beyond the situation is often characterised as one of lack of research impact on practice or described as fraught with problems of implementation. It has been a source of frustration and bewilderment in the research community for decades, but also of continuous and hopeful attempts to remedy the situation.

One of the attempts in research on and with mathematics teachers has been to move closer the acts of teaching in schools and teacher education programmes. This includes attention to the important practices of selecting and using tasks and of orchestrating classroom communication in response to noticing students' mathematical thinking. The papers 
in the present issue align with these attempts, which is of obvious importance to the further development of the learning opportunities in schools and colleges.

In spite of the significance of directing research towards the immediate challenges of teaching, one may wonder whether we-as a field — are generally too optimistic about how and how much we may contribute to transforming teaching-learning practices in ordinary classrooms. Surely, focusing on key instructional practices may be helpful and collaboration between teachers and researchers may provide significant, local learning opportunities for both groups. The question is, however, what may be expected with regard to the general developmental potential. The notions of impact and implementation that are often used to describe our scholarly ambitions seem to carry connotations of effectively introducing measures of change across contexts. However, the experiences from the last 50 or 60 years, roughly the period in which mathematics education has been established as a field of research in its own right, suggest otherwise.

So maybe "impact" and "implementation" are not the best terms to use when talking about educational change. This suggestion is certainly not new, neither in mathematics education nor in other educational fields. More than a quarter of a century ago, Clandinin and Connelly argued that impact and implementation are not helpful for understanding how curricular texts may — and may not-inform instruction:

Teachers and students live out a curriculum; teachers do not transmit, implement, or teach a curriculum and objectives; nor are they and their students carried forward in their work and studies by a curriculum of textbooks and content, instructional methodologies, and intentions. An account of teachers' and students' lives over time is the curriculum, although intentionality, objectives, and curriculum materials do play a part in it. (Clandinin and Connelly 1992)

Drawing on Clandinin and Connelly's perspective on curriculum, I suggest that lives as they unfold in schools and classrooms are emerging social worlds in their own right. There may be cracks and openings in these dynamic and evolving structures that allow for other actors and artefacts to play a role, including curricular intentions and materials as well school leaderships, assessment systems, parent organisations and media discussions to name but a few. But whether and how this is case are delicate empirical questions. This perspective shifts the focus from classrooms as settings for the enactment of (possibly degenerate) versions of curricular intentions, to seeing them as social constellations in constant flux in which it is an open question if and how research-based reform initiatives are an issue at all.

To illustrate my point, I draw a parallel to Lakatos, whose book on "Proofs and refutations" has been a significant inspiration for the processual emphasis in the reform for decades (Lakatos 1976). In his book, Lakatos describes the development of the Euler formula for polyhedra. The proof of the formula is presented by the teacher in an imaginary classroom, but soon the students (called Alpha, Beta, Gamma, etc.) challenge the proof as well as the theorem itself. One of them comes up with a counterexample and argues that now he has falsified the theorem once and for all. The teacher, however, says that there is more to be said about this, and that proofs may be interesting "even if they do not accomplish their intended task. Columbus did not reach India but he discovered something quite interesting" (Lakatos 1976, p. 14). The morals of the story are that after Columbus, why does anyone ever expect to find what they look for? And after Columbus, who would ever give up looking, even if they cannot expect to find what they went looking for in the first place? 
Many years ago I wrote a piece in which I drew a parallel between Lakatos' reference to Columbus and developments in mathematics education (Skott 2009). The argument was that reform initiatives since the early 1960s have played important roles for how classroom practices developed, but hardly ever in the ways in which the reformers expected. This is so with regard to New Maths in the 1960s; to the constructivist revolution of the 1980s; and to the reform initiatives from after the turn of the century. It certainly seems that the emphasis on core teaching practices in research and on collaboration among teachers and between teachers and researchers in current professional development have more potential than previous research and development initiatives. In spite of that, I still think expectations of impact and implementation are misguided. In parallel to Lakatos and considering the relationships between reform initiatives and dominant teaching-learning practices, why would anyone expect to have the kind impact they intend to have? Comparing dominant teaching-learning practices 50 or 60 years ago with those of today, why would anyone give up trying to develop the field further, even if the outcomes run short of the expectations?

\section{References}

Cai, J., Morris, A., Hohensee, C., Hwang, S., Robison, V., Cirillo, M., et al. (2019). Research pathways that connect research and practice. Journal for Research in Mathematics Education, 50(1), 2-10.

Clandinin, D. J., \& Connelly, F. M. (1992). Teacher as curriculum maker. In P. W. Jackson (Ed.), Handbook of research on curriculum (pp. 363-401). New York: MacMillan.

Lakatos, I. (1976). Proofs and refutatations. The logic of mathematical discovery. Cambridge: Cambridge University Press.

Schoenfeld, A. (2009). Series editor's foreword: The soul of mathematics. In D. A. Stylianou, M. L. Blanton, \& E. J. Knuth (Eds.), Teaching and learning proof across the grades: A K-16 perspective (pp. xii-xvi). New York \& London: Routledge.

Skott, J. (2009). Theoretical loops in mathematics education: theory-practice relationships revisited. Asian Journal of Educational Research and Synergy, 1(2), 74-88.

Publisher's Note Springer Nature remains neutral with regard to jurisdictional claims in published maps and institutional affiliations. 